\title{
SUSTAINABLE UTILIZATION OF BIOPOLYMERS AND BIOCEMENT IN AGGREGATION OF GRANULAR MATERIALS
}

\author{
Asha Ramachandran ${ }^{1}$, Navdeep Kaur Dhami ${ }^{1}$ and Abhijit Mukherjee ${ }^{1}$ \\ (1) Department of Civil Engineering, Curtin University, Bentley, Western Australia \\ 6102
}

\begin{abstract}
Soil stabilisation through materials such as lime or cement have considerable environmental penalty due to high embodied energy of the cementitious material. Biogeotechnology allows cement formation with dramatically reduced carbon footprint and promises a sustainable soil improvement method. In the current study, investigations were performed to evaluate the effect of biopolymer Xanthan gum and Microbially Induced Calcite Precipitation (MICP) on cementation of sands as well as sand-clay mixtures individually as well as in combination. The unconfined compressive strength tests and micrographic analysis through scanning electron microscope and energy dispersive X-ray spectroscopy results revealed that synergistic effect of biopolymer and MICP resulted in superior performance. Water absorption test indicated that the Xanthan gum was susceptible to water attack and incorporation of MICP helped in addressing the concern. Therefore, the present study was successful in overcoming the individual limitations of biopolymer and MICP as a sustainable soil stabilisation technology.
\end{abstract}

Keywords: Biopolymer, xanthan gum, soil, stabilisation, microbial induced calcite precipitation

\section{INTRODUCTION}

Chemical stabilization is one of the most widely used methods of soil stabilization (Cabalar et al., 2018). Chemical stabilizers such as cement, lime, bitumen, fly-ash sodium silicate and granulated blast furnace slag belong to the category of conventional stabilizers and are used conventionally for soil stabilization (Chang and Cho, 2012, Khatami and O'Kelly, 2013;Basha et al., 2005). However, the carbon footprint associated with these stabilizers is a rising concern which must be addressed (Chang and Cho, 2012, Renjith et al., 2017, Suer et al., 2009). In addition to this, the particulate emissions arising from the use of cement, lime and flyash make it less 
sustainable in the long run. These stabilizers are also responsible for altering the $\mathrm{pH}$ of the soil, which can have an adverse effect on vegetation and ground water quality (Latifi et al., 2016, Ayeldeen et al., 2017). Moreover, conventional stabilizers generally induce brittle behaviour in the treated soils which is often undesirable (Latifi et al., 2017).

Bio-geotechnology is an emerging area which allows cement formation with dramatically reduced carbon footprint and promises sustainable soil improvement (DeJong et al., 2010, Chang et al., 2016, Khatami and O'Kelly, 2013). Microbially Induced Calcite Precipitation (MICP), the process by which microorganisms produce carbonates as part of their basic metabolic activities, has been shown to improve geotechnical properties of soils including mechanical strength, permeability reduction and liquefaction resistance (Noh et al., 2016). However, certain limitations of this technology including the brittle nature of calcite crystals as well as harmful byproducts such as ammonia have led researchers to explore alternative products.

Microbial biopolymers, produced by the fermentation of sugars by microorganisms have been applied in various geotechnical engineering applications such as hydraulic barriers, contaminant adsorption and for improvement of strength (Chen et al., 2015, Ayeldeen et al., 2017). They have immense potential in the reduction of drainage channel erosion, formation of grout curtains and prevention of piping in earth dams (Ayeldeen et al., 2017). Studies demonstrated that biopolymers such as xanthan gum, polyhydroxy butyrate (PHB), guar gum and polyglutamic acid (PGA) exhibit positive plugging effects (Chen et al., 2015). Previous studies demonstrated the strengthening effect of biopolymer Gellan gum and Xanthan gum on sand by creating artificial cohesion (Chang et al., 2016, Cabalar et al., 2018, Cabalar and Canakci, 2011). In sandy soil, biopolymers form surface coating on sand particles, fill the pore spaces and increase the particle to particle contact area (Chang et al., 2015).

Biopolymers have been reported to show stronger adhesion with clay particles through hydrogen bonding leading to strong sorption and microstructural interaction(Chang et al., 2016). The strength of sand-clay mixtures has been reported to increase by the addition of biopolymers unlike that of pure sand or clay alone (Chang and Cho, 2018, Cabalar et al., 2018). The synergistic effect is due to the flocculation of fine particles as well as the interconnection between fine and coarse particles (Chang and Cho, 2018). Studies have also demonstrated the importance of complete drying in order to achieve maximum strength for biopolymer treated soils (Swain et al., 2018) as the strength of biopolymers has been found to be dependent on water content (Chang et al., 2015).

Although both bacterial carbonates and biopolymers have shown immense potential for different applications in improving the properties of soils, synergism of both these natural technologies can help overcome the individual limitations and lead to novel material synthesis with improved resistance to both mechanical and chemical loading. The current study investigated the performance of individual as well as 
combined technologies for cementation of sands as well as sand-clay mixtures using biopolymer Xanthan gum and bacterial carbonates resulting in a sustainable soil stabilization technology. A combination of mechanical, chemical and microscopy investigation was performed to gain better insights into the mechanism of stabilization.

\section{EXPERIMENTAL INVESTIGATION}

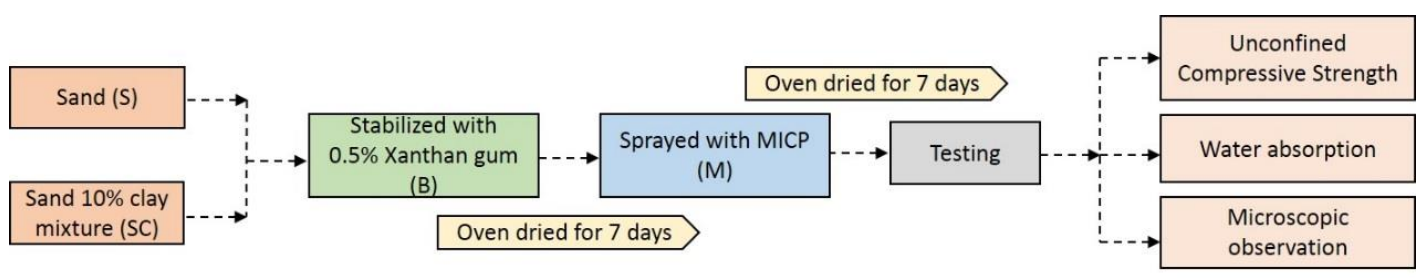

Fig.1 Outline of experimental investigation

In the experimental investigation, soils were subjected to stabilization via biopolymer Xanthan gum. The biopolymer stabilized samples are prone to softening upon water absorption which lead to loss in compressive strength. Therefore, surface coating with MICP was carried out to reduce moisture permeation (Porter et al., 2018a). The process of MICP was initiated by spraying the bacterial and cementation media (Table 2) and continued for a period of 21 days. The biopolymer stabilized MICP treated samples were subjected to destructive testing (UCS), water absorption tests as well as microscopic observation via scanning electron microscopy.

\subsection{Materials and Methods}

Manufactured sand was obtained from Cook Industrial Minerals, Western Australia. The grain size analysis of the sand revealed that the particle size of the sand varied between $0.45 \mathrm{~mm}$ and $0.075 \mathrm{~mm}$ (Fig 1). Kaolin clay was chosen in the present study due to its less reactive nature with water and significantly low shrinkage and swelling as compared to other clay minerals such as montmorillonite (Du et al., 2013, Latifi et al., 2017). The prestige line of kaolin clay was supplied by Sibelco, Australia and the particle size distribution as well as the chemical composition of the clay is listed in Table 1.The biopolymer used in the study, xanthan gum was sourced from Sigma Aldrich, NSW, Australia. Xantham gum is formed via the fermentation of glucose or sucrose using the bacterium Xanthomonas campestri and displayed high tensile strength. The urease producing bacterial strain, Sporosarcina pasteurii (ATCC 11859) was used in the current study. Dry density of the soils stabilized with biopolymer was obtained using modified Proctor density testing according to AS 1289.5.1.1.The addition of biopolymer to soil generally decreases the dry density and increases the optimum moisture content (OMC) of the soil mix (Ayeldeen et al., 2017). 


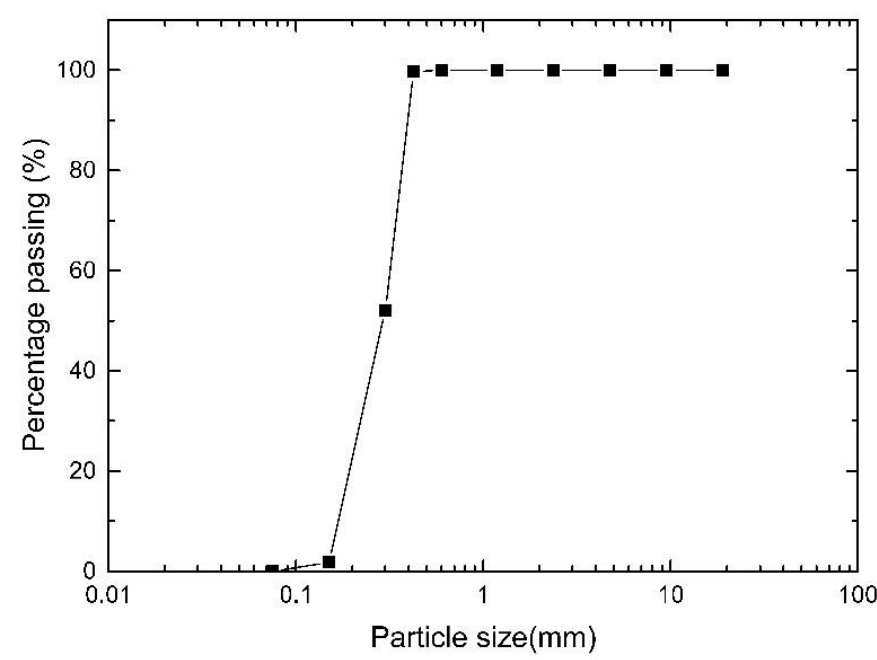

Fig 2. Particle size distribution of the manufactured sand

Table 1. Particle size distribution and chemical composition of the clay

\begin{tabular}{|l|l|}
\hline Particle size ( $\boldsymbol{\mu m})$ & Percentage passing (\% weight) \\
\hline 53 & 99.4 \\
\hline 20 & 97.8 \\
\hline 10 & 95.9 \\
\hline 5 & 90.3 \\
\hline 2 & 75.7 \\
\hline 1 & 63.6 \\
\hline $\mathrm{Chemical}$ analysis & Composition (\% Weight) \\
\hline $\mathrm{SiO}_{2}$ & 46.7 \\
\hline $\mathrm{Al}_{2} \mathrm{O}_{3}$ & 36.1 \\
\hline $\mathrm{TiO}_{2}$ & 0.8 \\
\hline $\mathrm{Fe} \mathrm{O}_{3}$ & 0.9 \\
\hline $\mathrm{CaO}$ & 0.7 \\
\hline $\mathrm{MgO}$ & 0.4 \\
\hline $\mathrm{K}_{2} \mathrm{O}$ & 0.4 \\
\hline $\mathrm{Na} 2 \mathrm{O}$ & 0.1 \\
\hline
\end{tabular}


Table 2. Details of bacterial media and cementation media used for MICP

\begin{tabular}{|l|l|l|}
\hline & Composition & Concentration \\
\hline \multirow{3}{*}{$\begin{array}{l}\text { Bacterial } \\
\text { media }\end{array}$} & Sporosarcina pasteurii(ATCC 11859) & $0.8<\mathrm{OD}_{600}<1.5$ \\
\cline { 2 - 3 } & Yeast extract & $20 \mathrm{~g} / \mathrm{L}$ \\
\cline { 2 - 3 } & Ammonium sulphate & $10 \mathrm{~g} / \mathrm{L}$ \\
\cline { 2 - 3 } & Tris base (pH 9) & $0.13 \mathrm{M}$ \\
\hline \multirow{3}{*}{$\begin{array}{l}\text { Cementation } \\
\text { media }\end{array}$} & Calcium chloride & $0.5 \mathrm{M}$ \\
\cline { 2 - 3 } & Urea & $0.5 \mathrm{M}$ \\
\cline { 2 - 3 } & Yeast extract & $1 \mathrm{~g} / \mathrm{L}$ \\
\hline
\end{tabular}

Table 3. Maximum dry density and optimum moisture content of samples

\begin{tabular}{|l|l|l|}
\hline Sample designation & MDD(g/cc) & OMC (\%) \\
\hline Sand (S) & 1.60 & 9.60 \\
\hline Sand +0.5\% xanthan gum (SB) & 1.63 & 11.30 \\
\hline Sand+10\% kaolin (SC) & 1.80 & 9.70 \\
\hline Sand +10\% kaolin +0.5\% xanthan gum (SBC) & 1.79 & 14.00 \\
\hline $\begin{array}{l}\text { Sand+10\% kaolin+0.5\% xanthan gum+ MICP } \\
\text { (SBCM) }\end{array}$ & NA \\
\hline Sand+0.5\% xanthan gum+ MICP (SBM) & NA \\
\hline
\end{tabular}

\subsection{Specimen Preparation}

Xanthan gum ( $0.5 \%$ dry weight of soil) was mixed with water (at required OMC) with continuous stirring on a hot plate at over $70^{\circ} \mathrm{C}$ to prevent agglomeration (Chang et al., 2015). It was hand-mixed with desired amount of sand/sand-clay mixture into a cylindrical mould of $50 \mathrm{~mm}$ dimeter and $100 \mathrm{~mm}$ height in 3 layers to achieve the desired maximum dry density. Each layer was scarified before addition of the next layer to ensure good bonding between the layers. The sample was allowed to cure in an incubator maintained at $60^{\circ} \mathrm{C}$ to allow hardening of xanthan gum for a period of 7 days.

After ensuring that the samples were completely dry, the MICP treatment was commenced. Sporosarcina pasteurii was growth in an ammonium-yeast extract media (Bernardi et al., 2014) maintained at $37^{\circ} \mathrm{C}$ and $180 \mathrm{rpm}$.Subsequently, $10 \mathrm{~mL}$ of the solution was sprayed on the outer surface area of the cylindrical specimens and the sample was incubated at $37^{\circ} \mathrm{C}$ for 6 hours. This was followed by the spraying of cementation media $(10 \mathrm{~mL})$ twice a day for a period of 4 days (Porter et al., 2018a). The cycle was repeated every 5 days for a total duration of 21 days. The samples were cement capped and taken for further testing.

\subsection{Unconfined Compressive Strength (UCS)}

UCS testing was carried out according to AS 5101.4 on a universal testing machine (Shimadzu AGS-X) of $10 \mathrm{kN}$ capacity. The specimen was compressed at a constant displacement of $1 \mathrm{~mm} / \mathrm{min}$ until failure. From the tests, secant modulus of elasticity 
(E50) was obtained from the corresponding stress-strain graphs corresponding to half of Unconfined Compressive Strength $\left(\mathrm{q}_{\mathrm{u}}\right)$ (Du et al., 2013, Chang et al., 2017).

\subsection{Microstructural Analysis}

To gain a better understanding of the interaction between biopolymer- clay- MICPsand systems, a small portion from the outer crust of the specimen was taken for analysis by employing SEM-EDS (Scanning Electron Microscopy-Energy Dispersive Spectroscopy ). The samples were mounted on aluminium stubs and sputtered with 10 $\mathrm{nm}$ thick platinum coating to provide conductivity through the sample. A Zeiss Neon 40 EsB dual beam FESEM (Field Emission Scanning Electron Microscope) was employed for imaging at $15 \mathrm{kV}$ and aperture size of $60 \mu \mathrm{m}$.

\subsection{Water Absorption Test}

Resistance to water absorption was determined according to AS 5101.5. After MICP spraying, the samples were oven dried at a temperature of $60^{\circ} \mathrm{C}$ for $72 \mathrm{~h}$. The dry mass of the sample was recorded and then the sample was immersed in standing water of 1 $\mathrm{cm}$ height. The intake of water by the specimen was continuously for 24 hours (Porter et al., 2017).

\section{RESULTS AND DISCUSSION}

\subsection{Stress- Strain Behaviour}

The stress-strain behaviour of biopolymer treated sand and sand clay mixtures are reported (Figure 3). Inter particle strengthening in sand is a result of formation of high tensile strength biopolymer films between the sand particles as observed in the Scanning electron micrographs (Figure 5). The incorporation of $10 \%$ clay (sample SBC) into sand significantly improved the strength of biopolymer treated samples. Hence, it can be concluded that the biopolymer incorporation improves the mechanical behaviour of the clay particles leading to a composite material with a superior performance under mechanical loading. In case of sand, $0.5 \%$ biopolymer is not sufficient to fill the large voids resulting in lower strength without the addition of clay. In case of sand-clay mixture, the clay acts as a filler material thereby facilitation the targeted bonding of the biopolymer. The surface coating by MICP significantly increased the strength in sand clay mixtures and the samples withstood higher strain (Figure 3). However, the sand treated with biopolymer and MICP (SBM) was weak in compression due to biopolymer swelling induced by MICP surface coating. Hence, the mechanical behaviour of sand clay mixtures stabilized with biopolymer can be further increased by synergising it with MICP surface coating. The MICP surface coating does not play a significant role in the case of sand stabilized with biopolymer due to high moisture retention. 

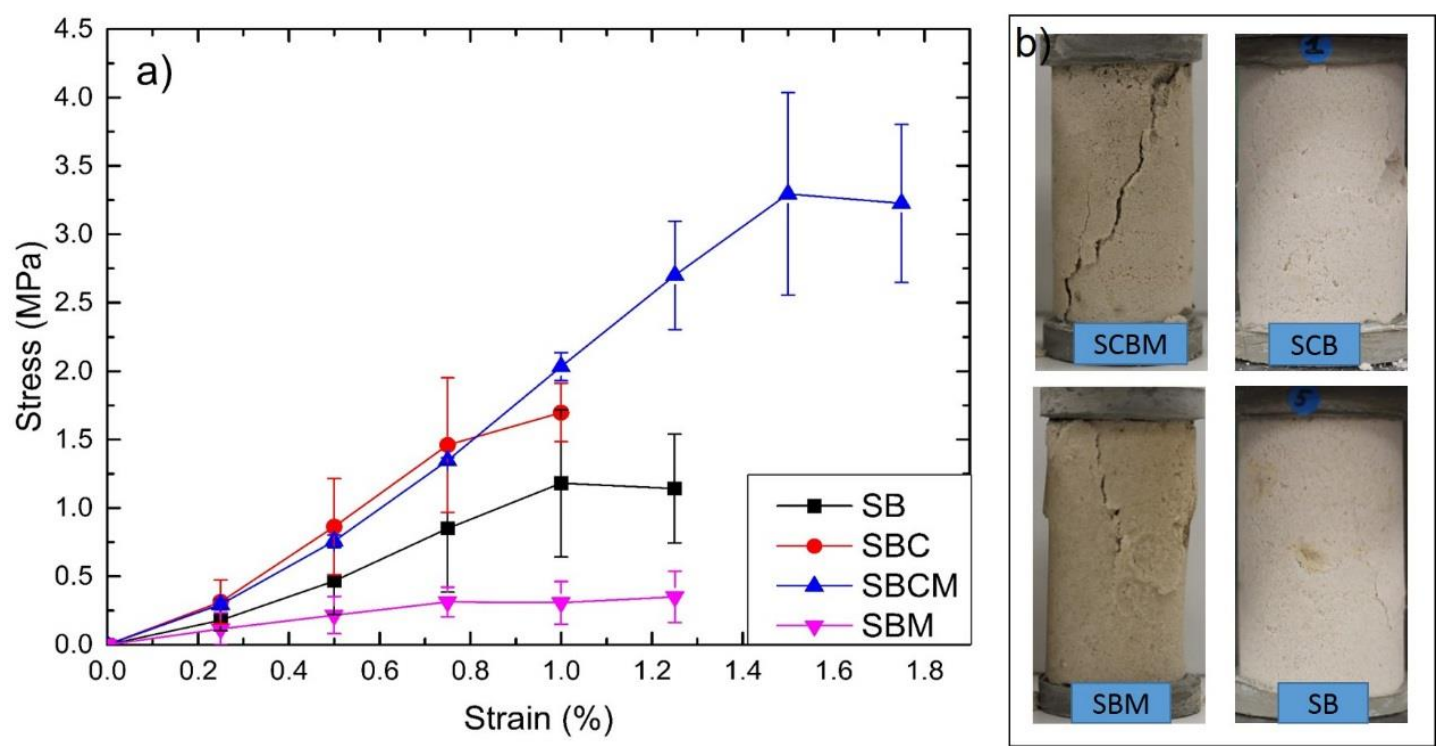

Fig 3. a) Stress-strain graphs and b) failure images of the stabilized sand and sand clay mixtures.

\subsection{Unconfined Compressive Strength and Secant Modulus}

The average secant modulus and UCS of the biopolymer treated sand increased with the addition of clay (Figure 4). Even small amount of xanthan gum can produce significant increase in compressive strength due to high specific surfaces providing interaction between clay particles (Cabalar et al., 2018). The UCS and secant modulus of sand clay mixture with MICP surface treatment was the maximum (Figure 4). Therefore, the brittle nature of calcite crystals and ductile behaviour of biopolymer perform well in synergy under compressive loading. The reduction in moisture absorption of these samples could also be a contributing factor for the increased performance under compressive loading (Porter et al., 2018a).
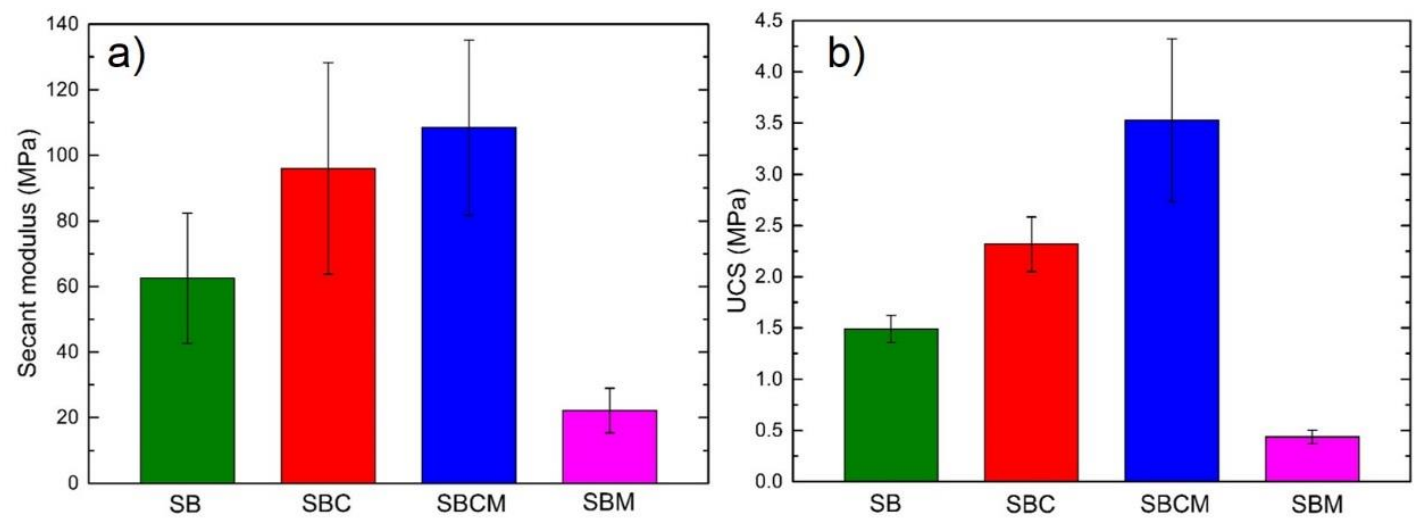

Fig 4. a) Secant modulus and b) Unconfined Compressive strength of stabilized samples 


\subsection{Water Absorption and FT-IR Spectroscopy}

The susceptibility of biopolymers to water attack is a major drawback while employing it as a stabilizer for practical applications. The interaction with water due to hydrophilic interactions result in swelling and subsequent reduction in the strength and stiffness of the stabilized sample. The results of the water absorption testing has been recorded in Figure 5 a).The biopolymer treated sand collapsed immediately upon exposure to water. It is well established that sandy soils stabilized with xanthan gum are more sensitive to water attack due to disruption of biopolymer-soil matrix caused by water ingress (Chang et al., 2015). The addition of clay helped in improving the resistance against water attack due to the direct hydrogen bonding between the biopolymer and clay particles. However, MICP surface coating improved the resistance to water attack for the samples treated with biopolymer both in the presence as well as absence of clay. The biopolymer treated sand clay mixture subjected to MICP treated displayed the lowest percentage of water absorption even after 24 hours. This clearly demonstrated the significance of MICP surface coating in soils stabilized with biopolymers.
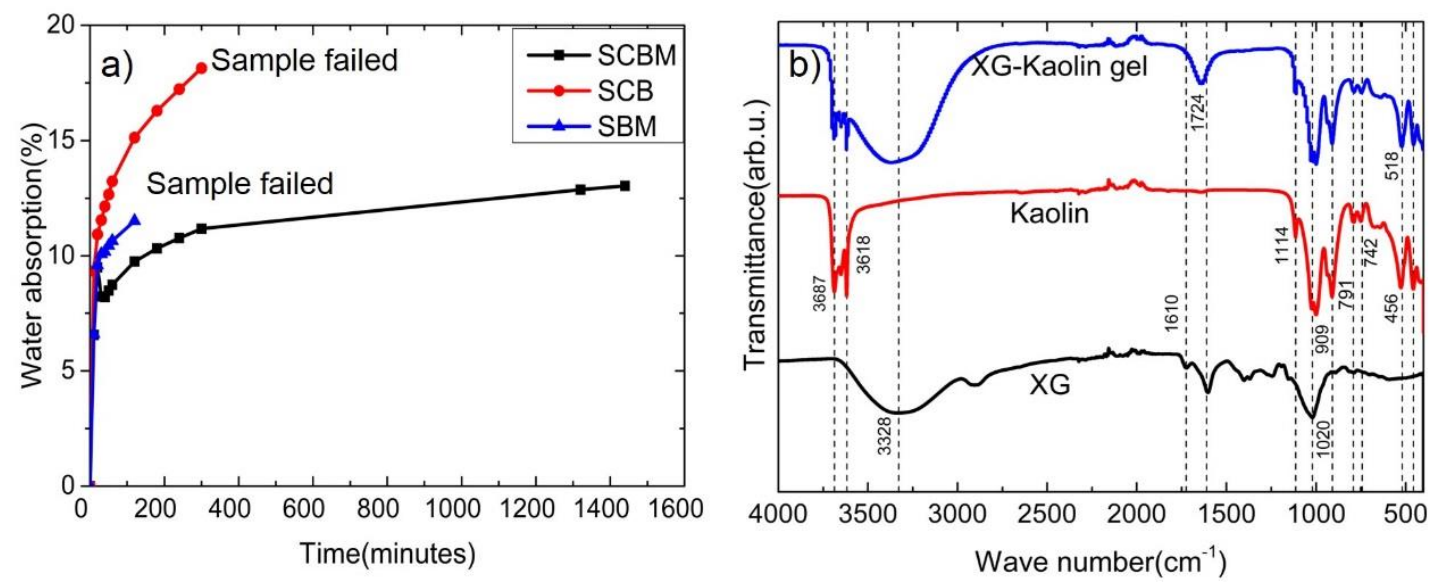

Fig 5.a) Water absorption of samples after 24 hours of submergence b) FTIR spectroscopy of xanthan gum, kaolin and xanthan gum-kaolin gel.

The results of FT-IR analysis of the clay, xanthan gum and the clay-biopolymer composite are shows in figure $5 \mathrm{~b}$ ). The FT-IR spectrum of xanthan gum shows peaks at $3400 \mathrm{~cm}^{-1}, 2939 \mathrm{~cm}^{-1}$ and $990-1200 \mathrm{~cm}^{-1}$ which are common to all polysaccharides (Faria et al., 2011). Typically for clays, the adsorption bands at $470 \mathrm{~cm}^{-1}, 540 \mathrm{~cm}^{-1}$ and $914 \mathrm{~cm}^{-1}$ are assigned to Si-O-Si bending vibration (Rong et al., 2008). It has been observed that xanthan monomers can directly bond to clay particles through cation bridging as well as hydrogen bonding between the carboxyl group and the hydroxyl group of xanthan gum and charged clay particles (Latifi et al., 2017, Hamidi and Hooresfand, 2013). 


\subsection{Microscopic Investigation}

Microstructural analysis was carried out to elucidate the underlying mechanism of strength gain after biopolymer stabilization. Figure $6 \mathrm{a}$ ), b) and c) shows the micrographs of sand stabilized with xanthan gum and the formation of biopolymer clay matrix. Microscopic observations revealed that biopolymers filled the pore spaces as well as formed bridges between the sand grains which supports the increase the grain contact characteristics in soil (Cabalar et al., 2018). The biopolymer and clay formed a composite material, as seen clearly in the SEM images (Figure $6 \mathrm{~d}$ )). Previous research employing laser diffraction as well as surface area analysis demonstrate that flocculation of the clay particles took place in the presence of xanthan gum which decreased the surface area of clay particles (Latifi et al., 2017). Hence, the strengthening mechanism of biopolymer treated sand-clay mixture could be explained as a combined effect of xanthan gum matrix formation as well as the hydrogen bonding between clay particles.

The results of EDS mapping on the polished sample SBCM has been displayed in Figure 7. The calcium deposits in the figure are representative of the MICP treatment and the aluminium content is indicative of the clay present in the sample. Interestingly, the calcite formation occurs around the sand grain and forms bridges across the sand grains leading to an increase in strength. This observation supports the hypothesis that bacteria get deposited on rough surfaces and the calcite crystal formation begins from the grooves on the sand grains which are rougher as compared to the smooth biofilm layer or the clay particles (Porter et al., 2018b). Hence MICP surface coating played a major role in preventing inter-granular slip or rotation by securing bridges between the sand grains.
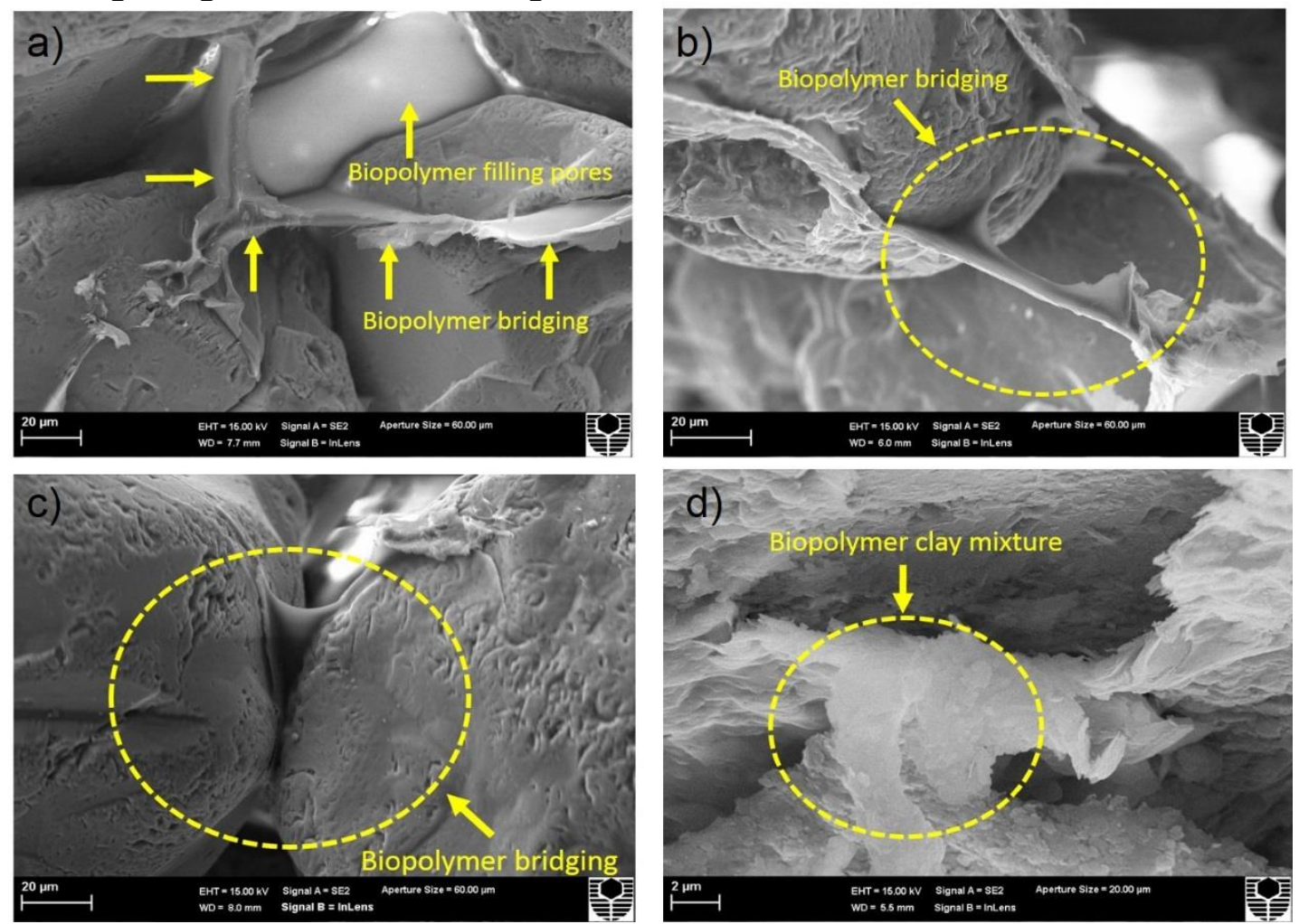
Fig 6.a) b) and c) Microscopic images of xanthan gum treated sand and d) sand clay mixture
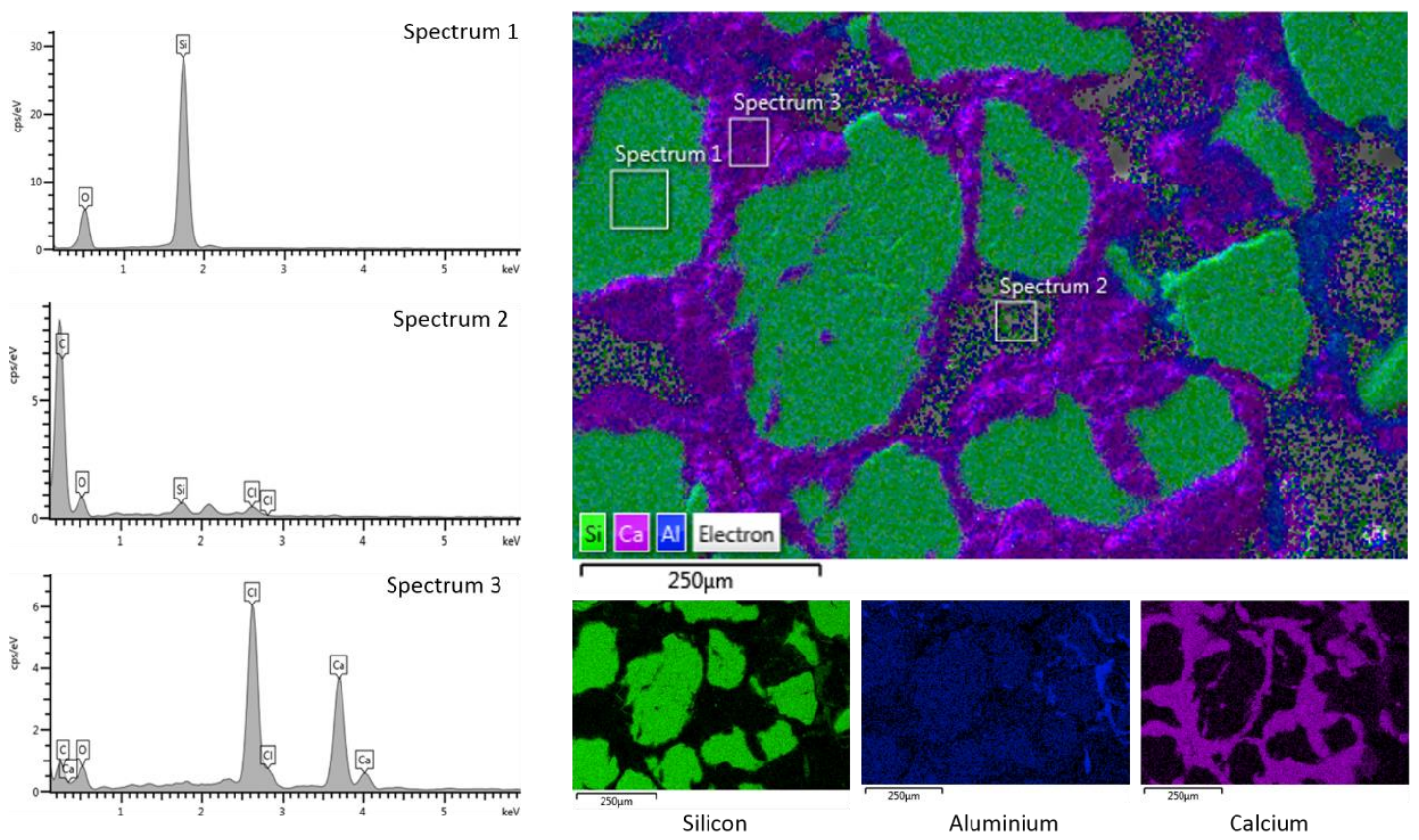

Fig 7.EDS mapping of biopolymer treated sand clay mixture stabilized with MICP.

Even though biopolymer technology is an emerging technology in the field of soil stabilization, the susceptibility of biopolymers to water attack limits its application as a permanent soil stabilizer. It could be employed in temporary construction applications such as dust suppression, temporary strengthening on unpaved ground and temporary roads. Moreover, insoluble biopolymers such as dextran and chitosan could be employed for such application and efforts should be made towards its commercialization in low cost applications. MICP is s growing technology in the field of geotechnical engineering, however the brittle nature of calcium carbonate crystals and large amount of laboratory grade materials consumed during the process limits its application. Therefore, synergizing the technologies pave way to the synthesis of a novel material will superior performance.

\section{CONCLUSION}

The experimental investigation is a novel attempt to synergise biopolymer stabilization with biomineralization for the stabilization of sand and sand-clay mixture. The following are the major conclusions from the study:-

1. Xanthan gum is not a preferred binder for sandy soils as they are prone to disintegration upon exposure to moisture.

2. The cementitious product formed by the interaction of biopolymer with clay led to flocculation of clay particles and filled the pore spaces, creating bridges between the sand particles and improving intergranular bonding. 
3. The clay-biopolymer composite resulted in superior performance against compressive loading and moisture ingress.

4. MICP surface coating proved beneficial for biopolymer stabilized sands clay mixtures in terms of mechanical performance and durability (against moisture induced disintegration).

5. Surface coating by MICP was helpful in addressing the water induced disintegration associated with biopolymer (Xanthan gum) stabilization.

\section{REFERENCES}

AYELDEEN, M., NEGM, A., EL-SAWWAF, M. \& KITAZUME, M. 2017. Enhancing mechanical behaviors of collapsible soil using two biopolymers. Journal of Rock Mechanics and Geotechnical Engineering, 9, 329-339.

BASHA, E. A., HASHIM, R., MAHMUD, H. B. \& MUNTOHAR, A. S. 2005. Stabilization of residual soil with rice husk ash and cement. Construction and Building Materials, 19, 448-453.

BERNARDI, D., DEJONG, J. T., MONTOYA, B. M. \& MARTINEZ, B. C. 2014. Bio-bricks: Biologically cemented sandstone bricks. Construction and Building Materials, 55, 462-469.

CABALAR, A. F., AWRAHEEM, M. H. \& KHALAF, M. M. 2018. Geotechnical Properties of a LowPlasticity Clay with Biopolymer. Journal of Materials in Civil Engineering, 30, 04018170.

CHANG, I. \& CHO, G.-C. 2012. Strengthening of Korean residual soil with $\beta-1,3 / 1,6$-glucan biopolymer. Construction and Building Materials, 30, 30-35.

CHANG, I. \& CHO, G.-C. 2018. Shear strength behavior and parameters of microbial gellan gum-treated soils: from sand to clay. Acta Geotechnica.

CHANG, I., IM, J. \& CHO, G.-C. 2016. Geotechnical engineering behaviors of gellan gum biopolymer treated sand. Canadian Geotechnical Journal, 53, 1658-1670.

CHANG, I., IM, J., LEE, S.-W. \& CHO, G.-C. 2017. Strength durability of gellan gum biopolymertreated Korean sand with cyclic wetting and drying. Construction and Building Materials, 143, 210-221.

CHANG, I., PRASIDHI, A. K., IM, J. \& CHO, G.-C. 2015. Soil strengthening using thermo-gelation biopolymers. Construction and Building Materials, 77, 430-438.

DU, Y.-J., JIANG, N.-J., LIU, S.-Y., JIN, F., SINGH, D. N. \& PUPPALA, A. J. 2013. Engineering properties and microstructural characteristics of cement-stabilized zinccontaminated kaolin. Canadian Geotechnical Journal, 51, 289-302.

FARIA, S., DE OLIVEIRA PETKOWICZ, C. L., DE MORAIS, S. A. L., TERRONES, M. G. H., DE RESENDE, M. M., DE FRANÇA, F. P. \& CARDOSO, V. L. 2011. Characterization of xanthan gum produced from sugar cane broth. Carbohydrate Polymers, 86, 469-476.

HAMIDI, A. \& HOORESFAND, M. 2013. Effect of fiber reinforcement on triaxial shear behavior of cement treated sand. Geotextiles and Geomembranes, 36, 1-9.

KHATAMI, H. R. \& O'KELLY, B. C. 2013. Improving Mechanical Properties of Sand Using Biopolymers. Journal of Geotechnical and Geoenvironmental Engineering, 139, 14021406.

LATIFI, N., HORPIBULSUK, S., MEEHAN, C. L., MAJID, M. Z. A. \& RASHID, A. S. A. 2016. Xanthan gum biopolymer: an eco-friendly additive for stabilization of tropical organic peat. Environmental Earth Sciences, 75, 825. 
LATIFI, N., HORPIBULSUK, S., MEEHAN, C. L., MAJID, M. Z. A., TAHIR, M. M. \& MOHAMAD, E. T. 2017. Improvement of Problematic Soils with Biopolymer\&\#x2014;An Environmentally Friendly Soil Stabilizer. Journal of Materials in Civil Engineering, 29, 04016204.

PORTER, H., BLAKE, J., DHAMI, N. K. \& MUKHERJEE, A. 2018a. Rammed earth blocks with improved multifunctional performance. Cement and Concrete Composites, 92, 36-46.

PORTER, H., DHAMI, N. K. \& MUKHERJEE, A. 2017. Synergistic chemical and microbial cementation for stabilization of aggregates. Cement and Concrete Composites, 83, 160-170.

PORTER, H., DHAMI, N. K. \& MUKHERJEE, A. 2018b. Sustainable road bases with microbial precipitation. Proceedings of the Institution of Civil Engineers - Construction Materials, 171, 95-108.

RENJITH, R., ROBERT, D., FULLER, A., SETUNGE, S., O'DONNELL, B. \& NUCIFORA, R. 2017. Enzyme based soil stabilization for unpaved road construction. MATEC Web Conf., $138,01002$.

RONG, X., HUANG, Q., HE, X., CHEN, H., CAI, P. \& LIANG, W. 2008. Interaction of Pseudomonas putida with kaolinite and montmorillonite: A combination study by equilibrium adsorption, ITC, SEM and FTIR. Colloids and Surfaces B: Biointerfaces, 64, 49-55.

SUER, P., HALLBERG, N., CARLSSON, C., BENDZ, D. \& HOLM, G. 2009. Biogrouting compared to jet grouting: Environmental (LCA) and economical assessment. Journal of Environmental Science and Health, Part A, 44, 346-353.

SWAIN, K., MAHAMAYA, M., ALAM, S. \& DAS, S. K. Stabilization of Dispersive Soil Using Biopolymer. 2018 Cham. Springer International Publishing, 132-147. 